\title{
Effects of annealing temperature on the microstructure and hardness of TiAlSiN hard coatings
}

\author{
WANG Xin, XU JianHua, MA ShengLi \& XU KeWei* \\ State Key Laboratory for Mechanical Behavior of Materials, Xi'an Jiaotong University, Xi'an 710049, China
}

Received March 1, 2010; accepted September 26, 2010

\begin{abstract}
TiAlSiN hard coatings were synthesized on high-speed steel using an arc ion enhanced magnetic sputtering hybrid system. The microstructure and hardness of the coatings at different annealing temperatures were explored by means of XRD, TEM, EDAX and Vickers indentation. The as-deposited TiAlSiN coatings were confirmed to be amorphous due to high depositing rate and low deposition temperature during the film growth. The transformation from amorphous to nanocomposites of nano-crystallites and amorphousness were observed after the annealing treatment, the microstructure of TiAlSiN coatings annealed at $800^{\circ} \mathrm{C}$ and $1000^{\circ} \mathrm{C}$ were consisted of crystalline hcp-AlN, fcc-TiN and amorphous phase, however, the coatings were only consisted of fcc-TiN and amorphous phase when annealing at $1100^{\circ} \mathrm{C}$ and $1200^{\circ} \mathrm{C}$. Meanwhile, the formation of $\mathrm{Al}_{2} \mathrm{O}_{3}$ was detected on the coating surface after annealing at $1200^{\circ} \mathrm{C}$ and it indicated the excellent oxidation resistance of the TiAlSiN coatings under the present experimental conditions. Furthermore, the average grain size of the TiAlSiN coatings after high temperature annealing even at $1200^{\circ} \mathrm{C}$ was less than $30 \mathrm{~nm}$ and the size increased with the increasing temperature. However, the hardness of the so-deposited coatings with $\mathrm{HV}_{0.2 \mathrm{~N}}=3300$ dramatically decreased with the increase of temperature and reached nearly to the hardness of TiN coatings with $\mathrm{HV}_{0.2 \mathrm{~N}}=2300$.
\end{abstract}

arc ion enhanced magnetic sputtering, annealing treatment, microstructure, hardness, TiAISiN hard coatings

Citation: Wang X, Xu J H, Ma S L, et al. Effects of annealing temperature on the microstructure and hardness of TiAlSiN hard coatings. Chinese Sci Bull, 2011, 56: 1727-1731, doi: 10.1007/s11434-010-4237-6

Ti-X-N (X=V, Al, W, Si, C, B, etc.) ceramic hard coatings had been investigated and proved to be with excellent properties by adding different metal or nonmetal elements in TiN matrix [1-6]. For example, TiAlN coatings improved film hardness and improved the oxidation temperature of TiN coatings from $550^{\circ} \mathrm{C}$ to $800^{\circ} \mathrm{C}$, which resulted from the formation of dense $\mathrm{Al}_{2} \mathrm{O}_{3}$ microfilm on top of the TiAlN coating. The dense $\mathrm{Al}_{2} \mathrm{O}_{3}$ layer effectively inhibited further diffusions of $\mathrm{O}$ atoms from top to inside of the coatings [7,8]. Adding Si into TiN lattice could inhibit grains growth in columnar manners and contributed to the formation of nanocomposite microstructure composed of TiN crystallites in nanometer embedded in amorphous $\mathrm{Si}_{3} \mathrm{~N}_{4}$ matrix under thermodynamic driven conditions. The properties of TiSiN coatings were considerably improved due to nanocomposite structure such

*Corresponding author (email: alexwx@ mailst.xjtu.edu.cn) as superhardness (40-105 GPa) and high thermal stability (up to $\left.1000^{\circ} \mathrm{C}\right)[9-11]$.

Recently multi-components TiAlSiN coatings had been synthesized to achieve better performance than both TiAlN and TiSiN coatings by different approaches such as magnetron sputtering, arc ion plating and other composite technologies [12-16]. The investigations on TiAlSiN hard coatings were focused on the optimization of deposition process and relationships among composition, microstructure and performance of the coatings, but less systematic investigations were carried on structural transformation and performance changes of TiAlSiN coatings during heat treatment from room temperature to high temperature (beyond $1000^{\circ} \mathrm{C}$ ). As is well known, the processing temperatures had significant effects on the performance of cutting and forming tools with hard coatings, thus thermal stability and properties of TiAl$\mathrm{SiN}$ coatings at high temperature were of special importance 
in experimental researches and industrial applications.

TiAlSiN coatings were deposited by arc ion enhanced magnetron sputtering in a hybrid system. The microstructural transformation and hardness change of the TiAlSiN coatings at different annealing temperature were studied and the mechanisms and influence factors were discussed.

\section{Experiments}

High-speed steel W18Cr4V was used as substrates and the size was $\Phi 24.5 \mathrm{~mm} \times 8 \mathrm{~mm}$, the hardness of substrates was HRC62. The substrates were polished and cleaned by acetone and alcohol respectively in ultrasound equipments before the coating deposition. TiAlSiN coatings were deposited in a SP-800 arc ion enhanced magnetron sputtering hybrid system. The targets used in the deposition included 2 Ti targets, 2 Si targets, 2 Al targets for magnetic sputtering and 1 columnar Ti target for arc evaporation, and the purity of all the targets was $99.99 \%$. The coating process parameters were shown as follows: ultimate vacuity was $5 \times 10^{-4} \mathrm{~Pa}$, work vacuity was $0.3 \mathrm{~Pa}$ with $\mathrm{Ar}$ and $\mathrm{N}_{2}$. Bias voltage on the substrates during the coating deposition was $-50 \mathrm{~V}$ and the sputtering power on different targets were shown as follows: $\mathrm{Ti}-3.6-3.8 \mathrm{~kW}, \mathrm{Al}-10 \mathrm{~kW}, \mathrm{Si}-2.3-2.5 \mathrm{~kW}$, arc current applied on the columnar Ti target was $60 \mathrm{~A}$. The temperature in the chamber during deposition was kept in constancy as $250^{\circ} \mathrm{C}$ and a Ti interlayer was deposited for 5 min followed by TiAlSiN deposition for $2 \mathrm{~h}$. The annealing treatment of TiAlSiN coatings was carried on in a pipe furnace at different temperatures as $800,1000,1100,1200^{\circ} \mathrm{C}$ in $\mathrm{N}_{2}$ atmosphere and the holding time was $1 \mathrm{~h}$.

The surface morphology of TiAlSiN coatings was explored by JSM-5600 scanning electron microscope and the coating thickness tested by SEM in cross-section photograph was $4.6-5 \mu \mathrm{m}$, the composition of the coatings was determined by EDAX attached to the SEM. The microstructure of the coatings was observed by JEM-3010 high resolution transmission electron microscope and RIGAKUD/MAX-2400 X-ray diffractometer was used to determine the phase transformation of the coatings before and after annealing. The size of crystallites in TiAlSiN coatings was analyzed and calculated by Scherer Formula according to the results from XRD tests. The coating hardness was tested by MH- 5 microhardness tester with Vickers indenter on condition that the load was $0.2 \mathrm{~N}$ and the load time was $5 \mathrm{~s}$. Each sample was tested five times and the mean value of test data was calculated as coating hardness.

\section{Results}

\subsection{Effects of the annealing treatment on microstruc- ture of TiAISiN coatings}

The composition of the TiAlSiN coatings studied here was determined by EDAX and the results were as follows: Ti-14.31 at\%, Al-26.3 at\%, Si-10.47 at\%, N-48.92 at\%, corresponding to chemical formula $\mathrm{Ti}_{0.28} \mathrm{Al}_{0.51} \mathrm{Si}_{0.21} \mathrm{~N}$.

The effect of the annealing temperature on the microstructure of TiAlSiN coatings was shown in Figure 1. The as-deposited coatings exhibited an obvious feature of amorphous structure as shown in Figure 1(a). But in Figure 1(b), it suggested that crystallization occurred in the coatings during annealing at $800^{\circ} \mathrm{C}$ and the peaks on X-ray diffraction spectra indicated the existence of hcp-AlN crystalline phase while the preferred orientations were (100) and (110). The (110) orientation was more preferential than (100) orientation. The preferential formation of AIN crystalline phase was due to prior nucleation and grain growth of AlN resulted from the high content of $\mathrm{Al}$ in the coatings. An obvious intensification of diffraction peak corresponding to AIN (100) was confirmed while there was no significant change on the diffraction peak of AlN (110) in Figure 1(c). It suggested that the preferential orientation of AlN crystalline phase changed to decrease system energy when annealing at $1000^{\circ} \mathrm{C}$. There were no peaks of AlN crystalline phase observed in Figure 1(d). Referring to the works of Karmi et al. [3], both hcp-AlN and fcc-AlN with high Al content were unstable at high temperature but the formation of hcp-AlN was more preferential. Therefore the disappearance of AlN crystalline phase in TiAlSiN coatings at $1100^{\circ} \mathrm{C}$ could be attributed to the decomposition of the unstable AlN and $\mathrm{Al}$ atoms probably dissolved in the TiN lattice resulted in the formation of solid solution TiAlN. According to Figure 1e, partial oxidation occurred in the coatings when annealing at $1200^{\circ} \mathrm{C}$ and oxidation product was $\alpha-\mathrm{Al}_{2} \mathrm{O}_{3}$. It suggested that the oxidation resistance of TiAl$\mathrm{SiN}$ coatings was excellent under the present experimental conditions. There was no obvious evidence of crystalline phase of $\mathrm{Si}$ and its compound and it could be deduced that $\mathrm{Si}$ in TiAlSiN coatings was in the form of $\mathrm{Si}_{3} \mathrm{~N}_{4}$ amorphous phase in consideration of the deposition conditions [12].

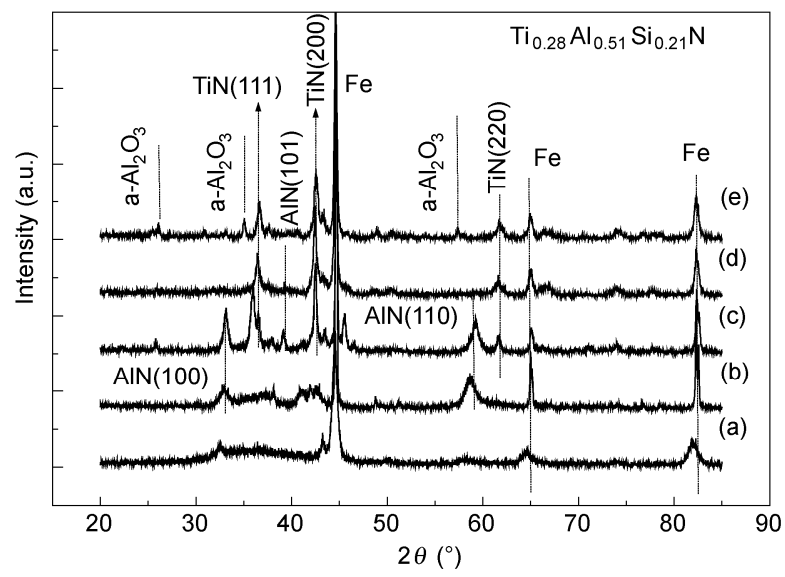

Figure 1 XRD spectra of the TiAlSiN coatings as-deposited (a), annealed for $1 \mathrm{~h}$ at $800^{\circ} \mathrm{C} \mathrm{(b),} 1000^{\circ} \mathrm{C}(\mathrm{c}), 1100^{\circ} \mathrm{C}(\mathrm{d})$, and $1200^{\circ} \mathrm{C}(\mathrm{e})$. 
The grain size of TiN crystallites in TiAlSiN coatings was calculated from XRD spectra and it showed that the grain size was below $30 \mathrm{~nm}$ even at $1200^{\circ} \mathrm{C}$ and increased with the increase of the annealing temperature in Figure 2.

Microstructure explored by HRTEM images and SAED patterns for as-deposited and annealed TiAlSiN coatings was shown in Figure 3. There was no obvious crystalline structure in HRTEM images and a typical pattern of amorphous phase was observed in SAED as shown in Figure 3(a). It suggested that the microstructure of the as-deposited TiAlSiN coatings was amorphous in accordance with the $\mathrm{XRD}$ results. The microstructure of the coatings transformed from amorphous to composite structure of nanocrystalline and amorphous after being annealed at $1000^{\circ} \mathrm{C}$ as shown in Figure 3(b). It showed a typical polycrystalline diffraction pattern in the SAED image and the

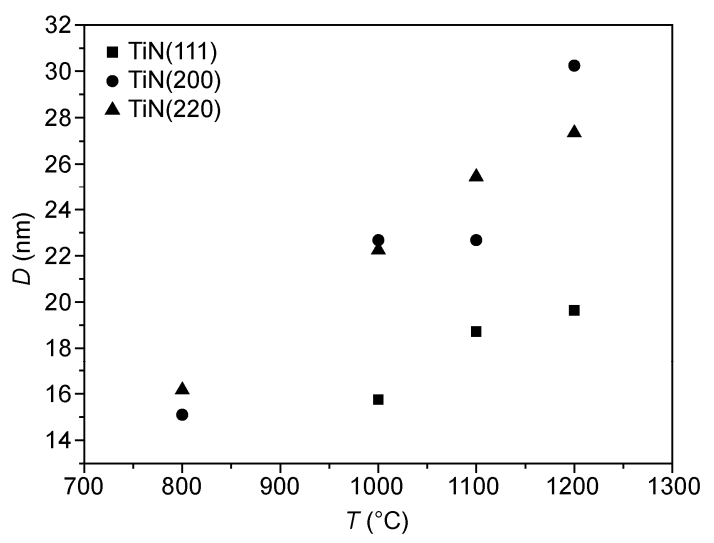

Figure 2 Calculated grain size of $\mathrm{TiN}$ in the TiAlSiN coatings from different peaks in XRD as a function of the annealing temperature.
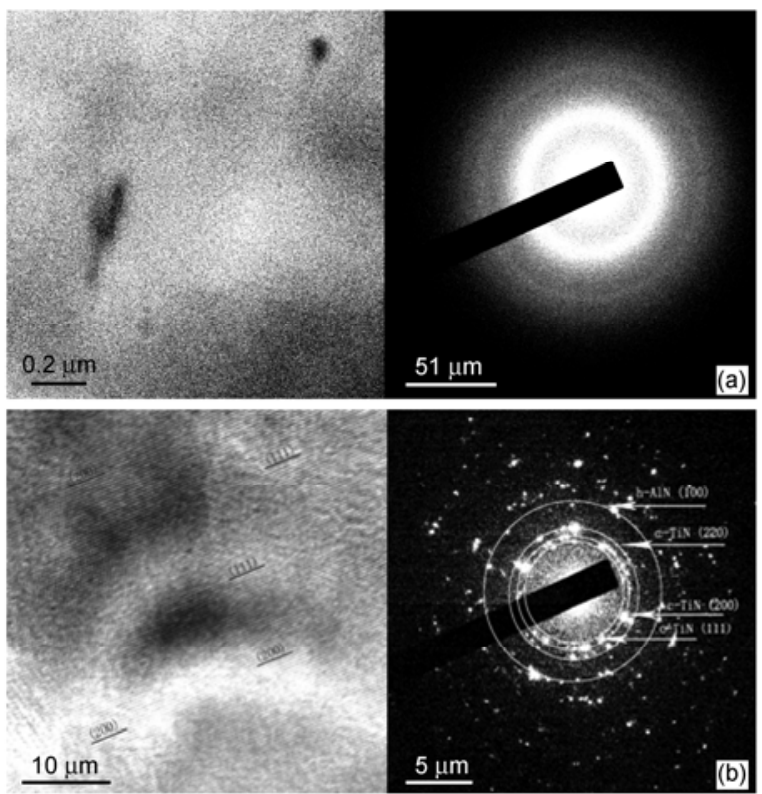

Figure 3 HRTEM images and SAED patterns of TiAlSiN coatings as-deposited (a) and annealed at $1000^{\circ} \mathrm{C}$ in $\mathrm{N}_{2}$ for $1 \mathrm{~h}$ (b). crystallites were confirmed as fcc-TiN and hcp-AlN by $\mathrm{XRD}$ and the corresponding interplanar spacing was calculated as follows: $d_{\mathrm{TiN}}(111)=0.2457 \mathrm{~nm}, d_{\mathrm{TiN}}(200)=0.2126$ $\mathrm{nm}, d_{\mathrm{TiN}}(220)=0.1503 \mathrm{~nm}, d_{\mathrm{AIN}}(100)=0.2703 \mathrm{~nm}$.

The hardness of the as-deposited TiAlSiN coatings was $\mathrm{HV}_{0.2 \mathrm{~N}}=3300$ higher than $\mathrm{TiN}$ and coating hardness decreased with the increase of the annealing temperature as shown in Figure 4. After being annealed at $800^{\circ} \mathrm{C}$, the coating hardness degraded to the level of TiN coatings and further decreased below $\mathrm{HV}_{0.2 \mathrm{~N}}=2000$ after being annealed at $1000^{\circ} \mathrm{C}$. The coating thickness was $4.6-5 \mu \mathrm{m}$ and the indentation depth estimated by the length of diagonal lines in indentation marks was less than 1/7 coating thickness. Thus the effect of the substrates on coating hardness was eliminated by choosing a relatively low indentation depth and low load of $0.2 \mathrm{~N}$. The decrease of coating hardness with increasing temperature could be attributed to the release of residual compressive stress induced in the coating deposition and the oxidants from partial oxidation when annealing at above $1100^{\circ} \mathrm{C}$.

\subsection{Discussions}

In Rebouta's works, the microstructure of TiAlSiN coatings deposited by RF and DC reactive magnetron sputtering was nano-crystallites/amorphous composite structure consisting of nc-TiAlN/a-Si ${ }_{3} \mathrm{~N}_{4}$ or nc-TiAlSiN/a-Si ${ }_{3} \mathrm{~N}_{4}$ and the coating hardness could reach the level of super hardness as $40-50$ GPa. Their results showed that the influence of the deposition rate, the ratio of ions/atoms, ions bombardment energy and substrate temperature on the formation of the nanocomposite microstructure was significant [14,17]. On the conditions of low deposition rate, high ratio of ions/atoms, high bombardment energy and high substrate temperature, the precipitation of $\mathrm{Al}$ and $\mathrm{Si}$ atoms from TiN lattice was easier due to relatively high mobility of surface atoms and it resulted in phase segregation of amorphous $\mathrm{Si}_{3} \mathrm{~N}_{4}$ and crystalline AIN at grain boundary and the formation of nano-crystallites/amorphous composite structure. Coatings with nanocomposite structure exhibited a super hardness above $40 \mathrm{GPa}$ and high elastic recovery above $80 \%$ according to the concept of superhard nanocomposite coatings presented by Veprek et al. [18-20]. On the contrary, the nanocomposite structure of nanocrystallites embedded in amorphous matrix could not form due to low mobility of atoms which resulted from high deposition rate, low bombardment energy and temperature. While a metastable solid solution of TiAlSiN would form in manner of pseudo crystal growth and the coating hardness could not be further improved.

The deposition rate of AEMS studied here was about 2.3-2.5 $\mu \mathrm{m} / \mathrm{h}$ which was 10 times higher than the rate in Rebouta's research and the coatings were bombarded intensely by the ions during the deposition process due to enhancement effect induced by the arc ions which also resulted in improved ionization of reactant gas atoms. As a result, 


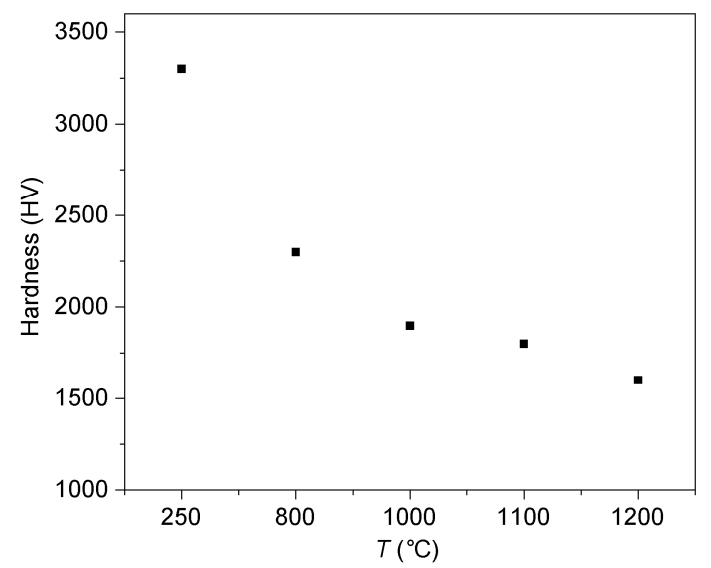

Figure 4 Effect of the annealing temperature on the hardness of TiAlSiN coatings.

the mobility of surface atoms decreased and there were no nanocrystallites/amorphous composite structure observed while a mono structure of amorphous had been confirmed in the as-deposited coatings. On the other hand, the diffusion of $\mathrm{Al}$ and $\mathrm{Ti}$ atoms and growth of crystallites could be inhibited thermodynamically by high $\mathrm{Si}$ content and low deposition temperature of $250^{\circ} \mathrm{C}[21,22]$. The microstructure of TiAlSiN coatings with different $\mathrm{Si}$ content prepared by composite approaches of arc ion plating and magnetron sputtering had been investigated by Park et al and it showed that the coating structure was amorphous with the ratio of $\mathrm{Si} /(\mathrm{Ti}+\mathrm{Al}+\mathrm{Si})$ beyond 0.19 which was in accordance with the results presented here [23].

The high hardness of as-deposited TiAlSiN coatings could be mainly attributed to biaxial compressive stress generated by intense ions bombardment during the coating deposition. Effects of biaxial compressive stress on the hardness of superhard $\mathrm{Me}_{1} \mathrm{~N} / \mathrm{Me}_{2}\left(\mathrm{Me}_{1}=\mathrm{Cr}, \mathrm{Zr}, \mathrm{V}, \mathrm{Ti} ; \mathrm{Me}_{2}=\right.$ $\mathrm{Ni}, \mathrm{Cu}$ )multilayer coatings synthesized by unbalanced magnetron sputtering had been investigated by Veprek et al. The hardness of the multilayer was beyond $40 \mathrm{GPa}$ and the compressive stress in the coatings was up to $7 \mathrm{GPa}$. While the coating hardness decreased significantly to the value of the corresponding bulks after annealing at $450^{\circ} \mathrm{C}$ and the compressive stress was completely released [24-27]. It suggested that the coating hardness was remarkably improved by the compressive stress induced by ions bombardment in the deposition process. The similar decrease of coating hardness after the annealing treatment was observed for TiAlSiN coatings prepared by AEMS and it could be explained by the mechanisms of stress relief.

The hardness of TiAlSiN coatings of which the microstructure was composite structure composed of nano crystallites and amorphous phase after the annealing treatment did not reach the level of super hardness. According to the concept of nanocomposite structure presented by Veprek, the microstructure with super hardness, high elasticity and thermal stability should be formed by fine nanocrystallites (below $10 \mathrm{~nm}$ ) embedded in very thin amorphous matrix (below $1 \mathrm{~nm}$ ) and a strong interface between amorphous and crystalline phase should be formed which could inhibit grain boundary sliding, dislocation movement, formation and propagation of cracks. The thickness of the amorphous layer was determined by its wetting ability with nanocrystallites and thick amorphous layer would degrade the mechanical properties of the coatings such as lower hardness and higher brittleness when the content of the amorphous phase was beyond the wetting limit [18-20,28]. For TiSiN coatings, the atomic fraction of Si corresponding to the wetting limit of amorphous phase was $0.07-0.1$ while the atomic fraction of $\mathrm{Si}$ in TiAlSiN coatings studied here was 0.21 and far beyond the wetting limit of amorphous phase with nanocrystalline AlN or TiN(TiAlN/TiAlSiN). It suggested that a thick amorphous layer was formed at the grain boundary after annealing, which significantly degraded the strength and hardness of TiAlSiN coatings. On the other hand, a dense amorphous layer could improve oxidation resistance and thermal stability of the coatings by inhibiting atoms diffusion at high temperature. As a conclusion, precise regulation and control of $\mathrm{Al}$ and $\mathrm{Si}$ contents and microstructure optimization of the coatings should be concerned simultaneously to prepare TiAlSiN coatings with outstanding combination properties such as high hardness, elasticity, thermal stability and oxidation resistance.

\section{Conclusions}

The microstructure of TiAlSiN coatings with a relatively high $\mathrm{Al}$ and Si content deposited by AEMS was mainly amorphous due to high deposition rate and the hardness of as-deposited coatings was $\mathrm{HV}_{0.2 \mathrm{~N}}=3300$ higher than TiN. A structural transformation from amorphous to composite structure of nanocrystallites/amorphous had been confirmed as the coatings were annealed at different temperature. The microstructure of TiAlSiN coatings annealed below $1000^{\circ} \mathrm{C}$ consisted of hcp-AlN, fcc-TiN and amorphous $\mathrm{Si}_{3} \mathrm{~N}_{4}$ while AlN crystalline phase vanished after being annealed at above $1000^{\circ} \mathrm{C}$ and the microstructure transformed to nc-TiAlN (TiAlSiN)/a-Si ${ }_{3} \mathrm{~N}_{4}$ composite structure. The grain size in the coatings increased with the increase of the annealing temperature and the coating hardness decreased either resulted from the release of residual compressive stress. After annealing at $1200^{\circ} \mathrm{C}$, partial oxidation had been observed and the oxidants were confirmed as $\mathrm{Al}_{2} \mathrm{O}_{3}$ which could further decrease the coating hardness.

This work was supported by the National Natural Science Foundation of China (50671079, 50531060), National Basic Research Program of China (2004CB619302) and Program for New Century Excellent Talents in University of China (NCET-04-0934).

1 Senna L F, Achete C A, Freire F L. Structural, chemical, mechanical and corrosion resistance characterization of TiCN coatings prepared by magnetron sputtering. Surf Coat Technol, 1997, 94-95: 390-397 
2 Musil J, Zemek J, Regent F, et al. Composition, structure, microhardness and residual stress of $\mathrm{W}-\mathrm{Ti}-\mathrm{N}$ films deposited by reactive magnetron sputtering. Thin Solid Films, 2002, 408: 136-147

3 Polakova H, Musil J, Mitterer C, et al. Structure-hardness relations in sputtered Ti-Al-V-N films. Thin Solid Films, 2003, 444: 189-193

4 Karvankova P, Veprek-Heijiman M G J, Veprek S, et al. Superhard nc-TiN/a-BN and nc-TiN/a-TiBx/a-BN coatings prepared by plasma CVD and PVD: A comparative study of their properties. Surf Coat Technol, 2003, 163-164: 149-156

5 Diserens M, Patscheidera J, Levy F. Mechanical properties and oxidation resistance of nanocomposite $\mathrm{TiN}-\mathrm{SiN}_{x}$ physical-vapor-deposited thin films. Surf Coat Technol, 1999, 120-121: 158-165

6 Musil J, Hruby H. Superhard nanocomposite $\mathrm{Ti}_{1-x} \mathrm{Al}_{x} \mathrm{~N}$ films prepared by magnetron sputtering. Thin Solid Films, 2000, 104-109: 365-369

7 Lugscheider E, Knotek O, Loffler F. Deposition of arc TiAlN coatings with pulsed bias. Surf Coat Technol, 1995, 76-77: 700-706

8 Kim Ch W, Kim K H. Anti-oxidation properties of TiAlN films prepared by plasma-assisted chemical vapor deposition and roles of Al. Thin Solid Films, 1997, 307: 113-119

9 Rebouta L, Tavares C J, Aimo R, et al. Hard nanocomposite Ti-Si-N coatings prepared by DC reactive magnetron sputtering. Surf Coat Technol, 2000, 133-134: 234-239

10 Vaz F, Rebouta L, Alves E, et al. Characterization of $\mathrm{Ti}_{1-x} \mathrm{Si}_{x} \mathrm{~N}_{y}$ nanocomposite films. Surf Coat Technol, 2000, 133-134: 307-313

11 Veprek S, Niederhofer A, Moto K, et al. Composition, nanostructure and origin of the ultrahardness in nc-TiN/a- $-\mathrm{Si}_{3} \mathrm{~N}_{4} / \mathrm{a}$ - and nc-TiSi nanocomposites with HV $=80$ to $105 \mathrm{GPa}$. Surf Coat Technol, 2000, 133-134: 152-159

12 Park In-W, Choi S R, Kim K H, et al. Deposition and mechanical evaluation of superhard Ti-Al-Si-N nanocomposite films by a hybrid coating system. Thin Solid Films, 2004, 447-448: 443-448

13 Kim G S, Kim B S, Hahn J H, et al. Effect of Si content on the properties of TiAl-Si-N films deposited by closed field unbalanced magnetron sputtering with vertical magnetron sources. Thin Solid Films, 2006, 506-507: 128-132

14 Cavalho S, Rebouta L, Alves E, et al. Microstructure of (Ti, Si, Al) N nanocomposite coatings. Surf Coat Technol, 2004, 177-178: 369-375

15 Chang Ch-L, Lee J-W, Tseng M-D. Microstructure, corrosion and tribological behaviors of TiAlSiN coatings deposited by catholic arc plasma deposition. Thin Solid Films, 2009, 517: 5231-5236

16 Andrade M F C, Martinho R P, Baptista A P M. Influence of the abrasive particles size in the micro-abrasion wear tests of TiAlSiN thin coatings. Wear, 2009, 267: 12-18

17 Ribeiro E, Cavalho S, Rebouta L, et al. Effects of ion bombardment on properties of D.C. sputtered superhard ( $\mathrm{Ti}, \mathrm{Si}, \mathrm{Al}) \mathrm{N}$ nanocomposite coatings. Surf Coat Technol, 2002, 151-152: 515-520

18 Veprek S, Reiprich S. A concept for the design of novel superhard coatings. Thin Solid Films, 1995, 268: 64-70

19 Veprek S, Reiprich S, Li S. Superhard nanocrystalline composite materials: The TiN/Si ${ }_{3} \mathrm{~N}_{4}$ system. Appl Phys Lett, 1995, 66: 2640-2645

20 Veprek S, Reiprich S, Li S Z, et al. Search for superhard materials: Nanocrystalline composites with hardness exceeding $50 \mathrm{GPa}$ Nano-structure Mater, 1998, 10: 679-689

21 Tanaka Y, Ichimiya N, Yamada Y, et al. Structure and properties of $\mathrm{Al}-\mathrm{Ti}-\mathrm{Si}-\mathrm{N}$ coatings prepared by the catholic arc ion plating method for high speed cutting applications. Surf Coat Technol, 2001, 146147: 215-221

22 Veprek S, Haussmann M, Reiprich S, et al. Novel thermodynamically stable and oxidation resistant superhard coating materials. Surf Coat Technol, 1996, 86-87: 394-401

23 Park In-W, Choi S R. Effects of Si addition on the microstructural evolution and hardness of Ti-Al-Si-N films prepared by the hybrid system of arc ion plating and sputtering techniques. J Vac Sci Technol A, 2003, 21: 895-899

24 Musil J, Vlcek J. Magnetron sputtering of alloy and alloy-based films. Thin Solid Films, 1999, 343: 47-50

25 Musil J, Karvankova P, Kasl J. Hard and superhard $\mathrm{Zr}-\mathrm{Ni}-\mathrm{N}$ nanocomposite films. Surf Coat Technol, 2001, 139: 101-109

26 Karvankova P, Eggs C, Veprek S. Thermal stability of $\mathrm{ZrN}-\mathrm{Ni}$ and CrN-Ni superhard nanocomposite coatings. Surf Coat Technol, 2001, 146-147: 280-285

27 Escudeiro S A, Karimi A, Schqtzeb A, et al. The role of hcp-AlN on hardness behavior of $\mathrm{Ti}_{1-x} \mathrm{Al}_{x} \mathrm{~N}$ nanocomposite during annealing. Thin Solid Films, 2004, 469-470: 339-334

28 Veprek S. The search for novel, superhard materials. J Vac Sci Technol A, 1999, 17: 2401-2420

Open Access This article is distributed under the terms of the Creative Commons Attribution License which permits any use, distribution, and reproduction in any medium, provided the original author(s) and source are credited. 